\title{
All-Trans Retinoic Acid Induces DU145 Cell Cycle Arrest through Cdk5 Activation
}

\author{
Eugene Lina,b Mei-Chih Chen ${ }^{a}$ Chih-Yang Huang c,d Shih-Lan Hsue \\ William J. Huang ${ }^{f}$ Mao-Sheng Lin ${ }^{b}$ Jungle Chi-Hsiang Wu ${ }^{b, g}$ Ho Lin ${ }^{a, d, h, i, j}$ \\ aDepartment of Life Sciences, National Chung Hsing University, Taichung, 'Department of Urology, \\ Chang Bing Show Chwan Memorial Hospital, Changhua, 'Graduate Institute of Basic Medical Science, \\ China Medical University, Taichung, 'Department of Biotechnology, Asia University, Taichung, \\ eDepartment of Education and Research, Taichung Veterans General Hospital, Taichung, 'Division of \\ Urology, Taipei Veterans General Hospital, Taipei, IRCAD Taiwan, Chang Bing Show Chwan Memorial \\ Hospital, Changhua, hDepartment of Medical Research, China Medical University Hospital, Taichung, \\ 'Department of Agricultural Biotechnology Center, National Chung Hsing University, Taichung, Taiwan, \\ jDepartment of Urology, University of Texas Southwestern Medical Center, Dallas, Texas, USA
}

\section{Key Words}

ATRA • Cdk5 • p27 • Prostate cancer • Cell cycle arrest

\begin{abstract}
Background/Aims: All-trans retinoic acid (ATRA), the active form of vitamin A, plays an important role in the growth arrest of numerous types of cancer cells. It has been indicated that cyclin-dependent kinase 5 (Cdk5) activity can be affected by ATRA treatment. Our previous results demonstrate the involvement of Cdk5 in the fate of prostate cancer cells. The purpose of this study is to examine whether Cdk5 is involved in ATRA-induced growth arrest of the castration-resistant cancer cell line DU145 through up-regulating Cdk inhibitor protein, p27. Methods: DU145 cells were treated with ATRA, and cell proliferation, protein expression, and protein localization of $\mathrm{Cdk5/p27}$ were examined. Cell proliferation and cell cycle distribution were also determined under Cdk5 inhibition induced by inhibitor or knockdown. Results: ATRA treatment inhibited DU145 cell proliferation and significantly increased p27 expression through Cdk5 up-regulation. Immunocytochemical data showed that a Cdk5 inhibitor reduced ATRA-triggered nuclear distribution of p27 in DU145 cells. The proliferation inhibition and G1 phase accumulation of DU145 cells were significantly increased by ATRA treatment, whereas Cdk5 inhibitor and siRNA could reverse these effects. Conclusions: Our results demonstrate that ATRA induced growth inhibition in castration-resistant prostate cancer cells through activating Cdk5 and p27. We hope this finding will increase the knowledge of prostate cancer treatment and can be applied in patients' nutritional control in the future.
\end{abstract}




\section{Introduction}

All-trans-retinoic acid (ATRA) is a vitamin A-related compound that can induce apoptosis in tumor cells from many types of cancer, including prostate cancer [1, 2], hematopoietic malignancies [3], neuroblastoma [4], cervical carcinoma [5], head and neck carcinomas [6], non-small cell lung cancers [7], breast cancer [8], bladder cancer [9], and ovarian cancer [10]. Prostate cancer is the most common cancer in the world diagnosed among elderly men [2]. The castration-resistant and metastatic state of prostate cancer so far remains incurable [2]. Growth arrest by retinoid-related compounds can lead to either terminal differentiation or apoptosis [11]. Long-term follow-up in clinical trials has also demonstrated that ATRA is effective in treating several types of cancer $[3,12]$. The mechanism by which ATRA acts on prostate cancer cells is still unclear. Although the application of ATRA in prostate cancer is still controversial, the molecular mechanism of ATRA is interesting to explore, especially from the perspective of a future combination therapy with other effective agents.

Cdk5 is a member of the cyclin-dependent kinase family. Like other cyclin-dependent kinase members, Cdk5 needs to bind to an activator to gain kinase activity $[13,14]$. One major activator for Cdk5 is p35, which was first reported in postmitotic neurons [15]. The critical role of the Cdk5-p35 complex is to support the development of the central nervous system, especially through the induction of neuronal differentiation [15]. In Alzheimer's disease, Cdk5 was found to be hyperactivated in neurons and to lead to neuronal death under oxidative stress, such as an increase in intracellular calcium [16]. In addition to the roles of Cdk5-p35 in the nervous system, numerous extra-neuronal functions of Cdk5-p35 have been discovered in recent years [17-19]. Our previous study indicated that Cdk5 regulates the growth of thyroid cancer cells [20] and that Cdk5 is also important to the ATRA-affected cell cycle distribution and fate of cancer cells [5, 21]. Subsequently, we found that the abnormal activation of Cdk5 triggered by intracellular calcium increase is involved in the apoptosis of prostate cancer cells [22]. Recently, our data also showed that a physiological activation of Cdk5 can phosphorylate and stimulate the androgen receptor and STAT3 and the growth of prostate cancer is therefore regulated [13, 23]. Brown et al. also indicate that ATRA-induced cell differentiation is correlated with the change in intracellular calcium [24]. Furthermore, Cdk5 is believed to be a differentiation inducer for leukemic cells [25]. Based on the connection between intracellular calcium and differentiation induction, it would be interesting to investigate how Cdk5 activation and ATRA effects are related. Interestingly, p27, one of the major Cdk inhibitors (CKIs), is required for the suppression of Cdk activity and to induce cell apoptosis [26]. Kawauchi et al. indicate that p27 participates in cortical neuronal migration as a downstream target of Cdk5, in addition to its involvement in cellcycle exit in cooperation with other conventional Cdks [27]. Based on these observations, p27 might become an indicator in this study to reflect whether ATRA affects Cdk5 and impacts the cell cycle of prostate cancer cells.

Our results demonstrate that Cdk5 activation is important to ATRA-induced cell cycle arrest of DU145 cells and that p27 might be an effector in this event. We hope the application of this finding, especially in patients' nutritional control, will help to increase the efficiency of clinical treatment in prostate cancer in the future.

\section{Materials and Methods}

\section{Cell Culture and Transfection of siRNA}

DU145 cell line (BCRC 60348), an androgen-independent prostate cancer cell line, was obtained from the Culture Collection and Research Center, Food Industry Research and Development Institute, Taiwan, Republic of China. DU145 cells were cultured in DMEM medium (Sigma Co., St. Louis, MO) plus 10\% fetal bovine serum (Hyclone, Logan, UT), $0.1 \mathrm{mM}$ non-essential amino acids, $1.0 \mathrm{mM}$ sodium pyruvate, and penicillin/streptomycin (Sigma Co.) at $37^{\circ} \mathrm{C}$ in a humidified atmosphere at $5 \% \mathrm{CO}_{2}$. Cells were passaged in a ratio of 1:5 every three days. sicdk5 and nonspecific control siRNAs were purchased from Dharmacon 
(Lafayette, CO) which are SMARTpool ${ }^{\mathrm{TM}}$-containing four SMART-selected siRNA duplexes. The siRNAs were transfected into DU145 cells using Lipofectamine ${ }^{\mathrm{TM}} 2000$ (Invitrogen Co., Carlsbad, CA) with 5 pmol siRNA $/ 10^{4}$ cells one day before treatment with ATRA $[5,22]$.

\section{Cell Proliferation Assay}

The modified colorimetric 3-(4, 5-dimethylthiazol-2-yl)-2, 5-diphenyltetrazolium bromide (MTT) assay was adapted to quantify the proliferation of DU145 cancer cells. Yellow MTT compound (Sigma Co.) was converted by living cells to form blue formazan, which is soluble in dimethyl sulfoxide. The intensity of blue staining in culture medium proportionally represented the number of living cells and was measured by optical density reader (Spectro MAX plus, Molecular Devices) at $570 \mathrm{~nm}$ [28].

\section{Quantitative Real-Time PCR}

Total RNA was extracted from DU145 cells by using a Miniprep Purification Kit (Genemark, Taiwan), and reverse transcription-PCR was performed by using a High-Capacity cDNA Reverse Transcription Kit (Applied Biosystems, Foster City, CA). For reverse transcription, $2 \mu \mathrm{g}$ of total RNA was used as the first strand cDNA template for the subsequent amplification. cDNA and primers were mixed within FastStart Universal SYBR Green Master (Roche Applied Science) and measured using a real-time PCR instrument (Applied Biosystems). Data presented by Ct values were analyzed and adjusted relative to levels of the $\beta$-actin house-keeping gene [29].

\section{Immunoblotting Analysis}

Cell lysates were produced in lysis buffer [20 mM Tris-HCl, pH 7.4, 1\% NP40, $137 \mathrm{mM} \mathrm{NaCl}, 50 \mu \mathrm{M}$ EDTA, protease inhibitor cocktail (Roche Co., Mannheim, Germany), and $1 \mathrm{mM}$ phenylmethanesulfonyl fluoride (PMSF, Sigma Co., St. Louis, MO)] for immunoblotting [20]. Protein samples were analyzed by direct immunoblotting (30 $\mathrm{g} / \mathrm{lane})$. Antibodies used included anti-Cdk5 antibody, (1:1,000, Santa Cruz Biotechnology, Santa Cruz, CA), anti-p27 antibody (1:2,500, BD Biosciences, Franklin Lakes, NJ), antiactin (1:2,000, MAB1501, Millipore, Billerica, MA), and peroxidase-conjugated anti-mouse or anti-rabbit antibodies (1:10,000, Jackson ImmunoResearch Laboratory, West Grove, PA). ECL detection reagent (Perkin Elmer Co., Boston, MA) was used to detect the immunoreactive proteins [5, 22].

\section{Immunocytochemistry}

DU145 cells cultured on coverslips were fixed, permeabilized, and blocked as previously described [30]. Primary antibodies (anti-Cdk5, Santa Cruz Biotechnology; anti-p27, BD Biosciences) diluted in 3\% BSA/PBS were incubated with coverslips overnight at $4^{\circ} \mathrm{C}$. Cells were washed in PBS and exposed to FITC- or TRITC-conjugated secondary antibodies (affinity purified goat anti-rabbit IgG, 1:200, Jackson ImmunoResearch Laboratory, West Grove, PA) for $1 \mathrm{~h}$ at room temperature. After extensive washing, coverslips were mounted in Gel/Mount medium (Biomeda Co., Foster City, CA) and observed by Leica confocal microscopy (LS200, Wetzlar, Germany). Quantification of the subcellular localization of Cdk5 and p27 was performed by immunofluorescence microscopy [31].

\section{Analysis of Cell Cycle Distribution}

Propidium iodide staining was used for DNA content measurement. DU145 cells, trypsinized and fixed in 70\% ethanol, were washed once with PBS and treated with RNase A (Sigma Co.) for $30 \mathrm{~min}$, followed by staining with propidium iodide $(0.1 \%$ sodium citrate, $0.1 \%$ Triton X-100, and $20 \mu \mathrm{g} / \mathrm{ml}$ propidium iodide, (Sigma Co.). DNA content was measured using flow cytometry (FACS Calibur, BD Co., Franklin Lakes, NJ). The percentage of cells in each phase of the cell cycle was analyzed by the software Cell Quest software (BD Co.) [5].

\section{Statistics}

All values are given as the means \pm S.E. of the means, and the means were tested for homogeneity by two-way analysis of variance. The differences between specific means were tested for significance by Student's $t$ test. The difference between two means was considered statistically significant when $p<0.05$ [32]. 


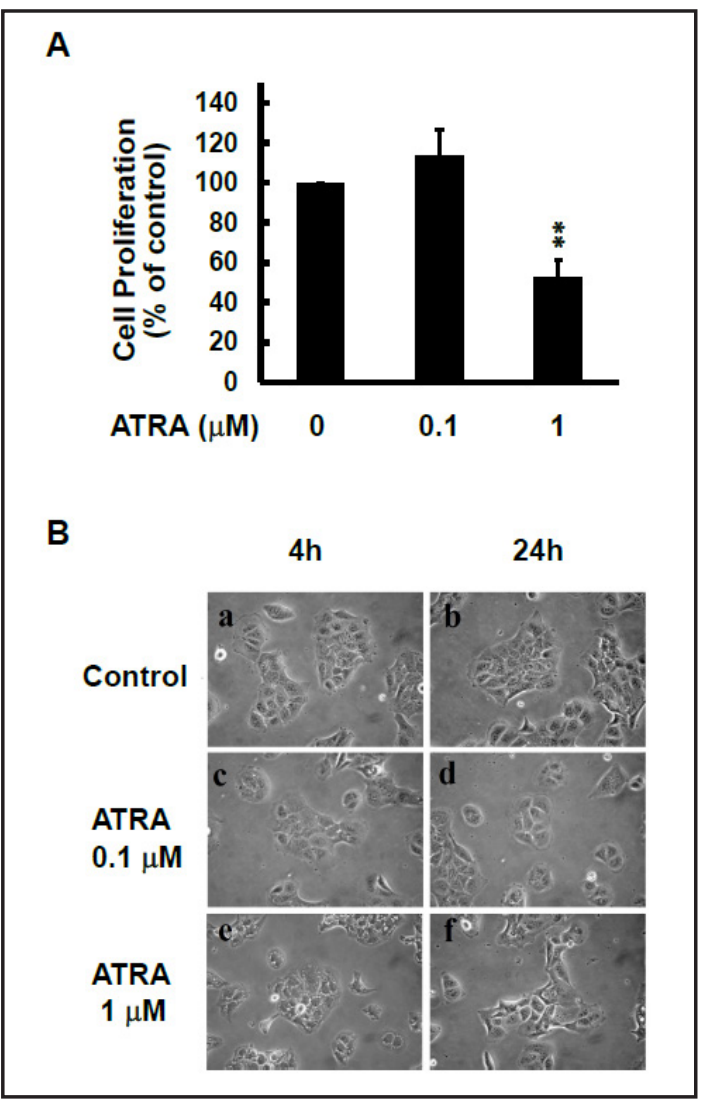

Fig. 1. ATRA induces proliferation inhibition and morphology change in DU145 cells. A. After 24 h-pretreatment of serum deprivation, DU145 cells were treated as follows: control (0.1\% DMSO) or ATRA $(0.1 \mu \mathrm{M}$ and $1 \mu \mathrm{M})$, for $24 \mathrm{~h}$. Cell proliferation was measured by MTT assay as described in "Materials and Methods" $(n=6)$. Data are represented as the means \pm S.E. of the mean; ${ }^{* *}, p<0.01$ versus ATRA $=0$ group. B. After 24 h-pretreatment of serum deprivation, DU145 cells were treated as follows: control (0.1\% DMSO), ATRA ( $0.1 \mu \mathrm{M}$ and $1 \mu \mathrm{M})$, for $4 \mathrm{~h}$ or 24 h. Phase contrast micrographs were recorded (80X).
A

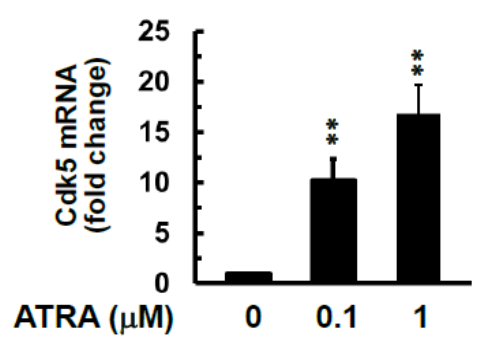

B

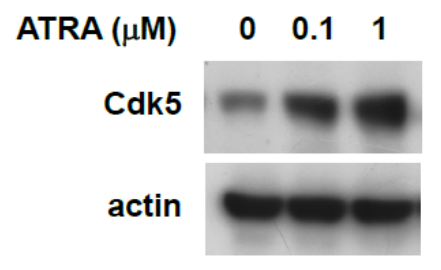

C

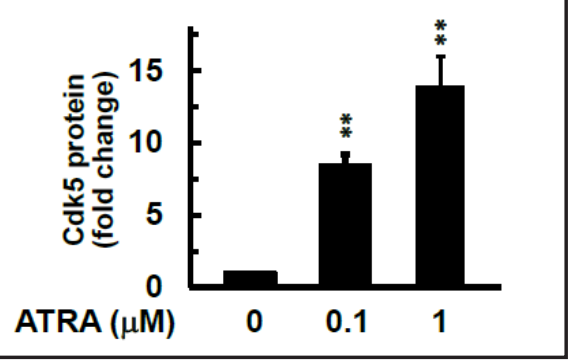

Fig. 2. ATRA induces Cdk5 expression in DU145 cells. After 24 h-pretreatment of serum deprivation, DU145 cells were treated as follows: control (DMSO, $0.1 \%)$ or ATRA $(0.1 \mu \mathrm{M}$ and $1 \mu \mathrm{M})$ for $24 \mathrm{~h}$. A. Cdk5 mRNA expression was detected by quantitative real-time PCR. Data were presented as the fold change compared to control levels. B. Cdk5 protein expression was detected by immunoblotting with a specific antibody, while actin served as an internal control. C. The quantitative results revealed the fold changes in the ratio of Cdk5 versus actin, while the ratio of the control group is 1 . The independent experiment was repeated 3 times. The data are represented as the means \pm S.E. of the mean; ${ }^{* *}, p<0.01$ versus ATRA $=0$ group.

\section{Results}

\section{ATRA affects proliferation and morphology of DU145 cells}

DU145 cells were cultured in 96 -well plates $\left(3 \times 10^{3}\right.$ cells/well $)$ under serum deprivation for $24 \mathrm{~h}$ before treatment with or without ATRA $(0.1 \mu \mathrm{M}$ and $1 \mu \mathrm{M})$ for $24 \mathrm{~h}$. Cell proliferation was measured by MTT assay $(n=6)$. As shown in Fig. 1A, $1 \mu$ M ATRA treatment significantly inhibited cell proliferation ( $p<0.01$ compared with the control group), while there is no significant change after $0.1 \mu \mathrm{M}$ ATRA treatment. In addition to proliferation, cell morphology after 4- and 24-h treatments with ATRA was also recorded by phase microscopy. As shown in Fig. 1B, treatment with ATRA for $24 \mathrm{~h}$ resulted in a spindle-like morphology and loosened attachment of the cells to the surface of the plate. 


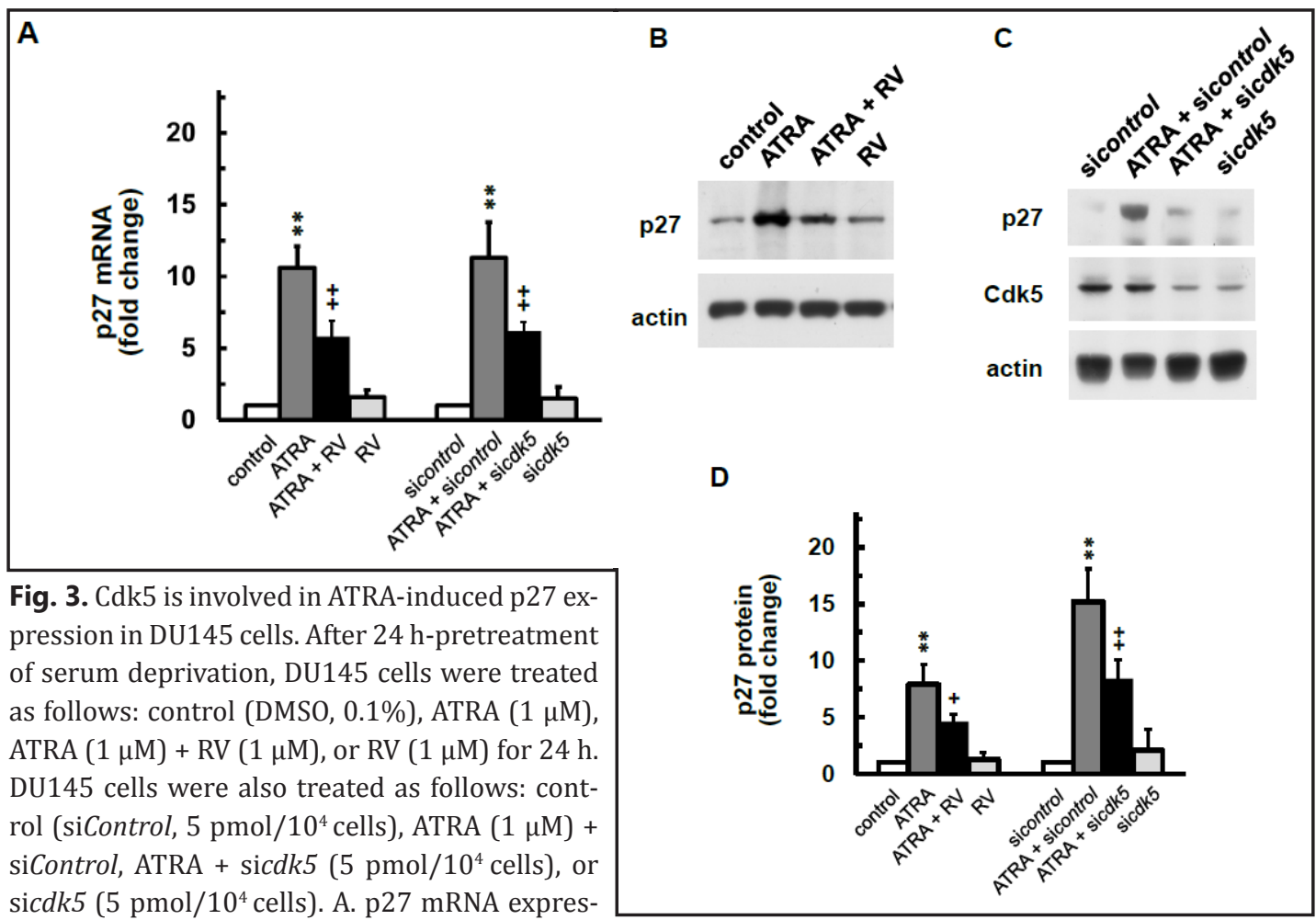
sicdk5 (5 pmol/10 ${ }^{4}$ cells). A. p27 mRNA expression was detected by quantitative real-time PCR. Data were presented as the fold change compared to control levels. B and C. Immunoblotting images of p27 and Cdk5 proteins were shown and actin served as an internal control. D. The quantitative results revealed the fold changes in the ratio of p27 versus actin, while the ratio of the control group is 1 . The independent experiment was repeated 3 times. The data are represented as the means \pm S.E. of the mean; ${ }^{* *}, p<0.01$ versus control group;,$+ p<0.05$ and,$++ p<0.01$ versus ATRA group.

\section{ATRA increases Cdk5 expression in DU145 cells}

After a 24-h pretreatment of serum deprivation, DU145 cells were treated with control (DMSO, $0.1 \%$ ), $0.1 \mu \mathrm{M}$ ATRA, or $1 \mu \mathrm{M}$ ATRA for $24 \mathrm{~h}$. ATRA treatment significantly increased both Cdk5 mRNA expression as detected by quantitative real-time PCR (Fig. 2A) and Cdk5 protein expression as detected by immunoblotting with specific antibody (Fig. 2B). The graph in Fig. $2 \mathrm{C}$ shows the quantitative results of protein expression with three replicates. ATRA affects Cdk5 mRNA and protein expressions in a dose-dependent manner. Because $\mathrm{Cdk} 5$ is a positive regulator of cell differentiation [25], this result suggests that Cdk5 might be involved in the ATRA-induced growth inhibition of DU145 cells.

\section{ATRA triggers 27 expression through Cdk5 up-regulation}

After a 24-h pretreatment of serum deprivation, DU145 cells were treated with control (DMSO, 0.1\%), $1 \mu \mathrm{M}$ ATRA, $1 \mu \mathrm{M}$ ATRA with $1 \mu \mathrm{M}$ roscovitine (RV, a Cdk5 inhibitor), or roscovitine alone for $24 \mathrm{~h}$. ATRA treatment significantly increased p27 mRNA expression. This ATRA-induced increase in p27 expression was attenuated by co-treatment with RV, while RV alone did not affect the control level of p27 expression (left panel, Fig. 3A). To further identify the role of Cdk5 in the ATRA-induced p27 increase, siRNA was used to knock down Cdk5 expression and the Cdk5 protein levels in cells after knocking down was shown in Fig. 3C. DU145 cells were treated with control (siControl, 5 pmol/10 $10^{4}$ cells), ATRA $(1 \mu \mathrm{M})$ + siControl, ATRA + sicdk5 (5 pmol/104 cells), or sicdk5 (5 pmol/104 cells). sicdk5 was able to attenuate ATRA-induced increase in p27 expression (right panel, Fig. 3A). Similar results were shown in p27 protein expression (Fig. 3B and 3C) and Fig. 3D shows the quantitative results from the data in Fig. 3B and Fig. 3C with three replicates. 


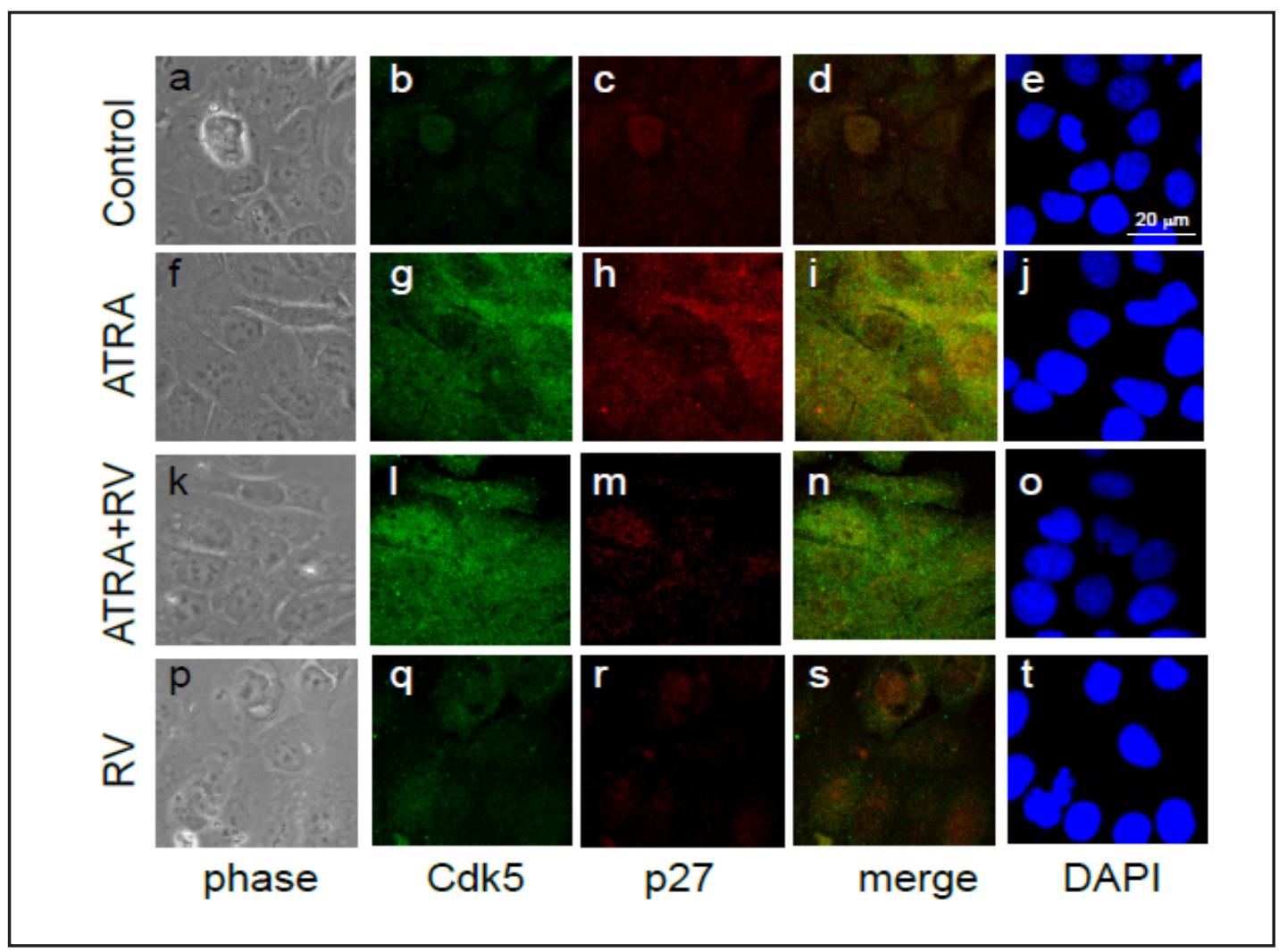

Fig. 4. ATRA affects protein expression and subcellular localization of Cdk5 and p27 in DU145 cells. After 24-h pretreatment of serum deprivation, DU145 cells were treated as follows: control (DMSO, 0.1\%), ATRA $(1 \mu \mathrm{M})$, ATRA $(1 \mu \mathrm{M})+\mathrm{RV}(1 \mu \mathrm{M})$, or RV $(1 \mu \mathrm{M})$ for $12 \mathrm{~h}$. The levels and subcellular localization of Cdk5 and p27 proteins were detected by immunocytochemistry with specific antibodies as described in "Materials and Methods". The images were captured by confocal microscope. Control group: a-e; ATRA group: f-j; ATRA+RV group: k-o; RV group: p-t.

ATRA-triggered changes in the subcellular distribution of Cdk5 and p27 are sensitive to Cdk5 activation

After a 24-h pretreatment of serum deprivation, DU145 cells were treated with control (DMSO, 0.1\%), $1 \mu \mathrm{M}$ ATRA, $1 \mu \mathrm{M}$ ATRA with $1 \mu \mathrm{M}$ RV, or $1 \mu \mathrm{M}$ RV alone for $24 \mathrm{~h}$. The subcellular distributions of Cdk5 and p27 were detected by immunocytochemistry with specific antibodies, and the images were captured by confocal microscope as described in Materials and Methods. The results showed that the ATRA treatments significantly increased the protein levels of Cdk5 (panel g, Fig. 4) and p27 (panel h, Fig. 4) while the levels of p27 protein in nucleus were remarkably increased. In the group of treatment with Cdk5 inhibitor (RV) and ATRA, although Cdk5 protein levels in cells were not affected, the intensity of p27 protein, especially in cytosol, was significantly reduced (panel m, Fig. 4). The intensity and localization of both Cdk5 and p27 proteins were comparable to the control group. This finding is similar to the data indicating the relationship between Cdk5 and p27 in neuronal cells [33] and might provide a possible mechanistic correlation between Cdk5 and the cell cycle arrest induced by ATRA in DU145 cells.

\section{ATRA-reduced cell proliferation can be reversed by Cdk5 inhibition}

To investigate the role of Cdk5 activity in ATRA-induced growth inhibition (Fig. 1A), the Cdk5 inhibitor RV was used as described in Fig. 3A. Cell proliferation was measured by the MTT assay $(n=6)$. ATRA treatment significantly decreased the proliferation of DU145 cells, whereas co-treatment with RV could completely reverse ATRA-induced effects (Fig. 


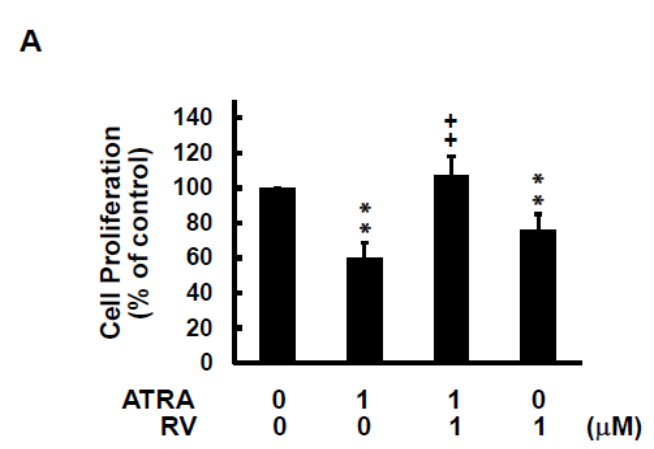

B

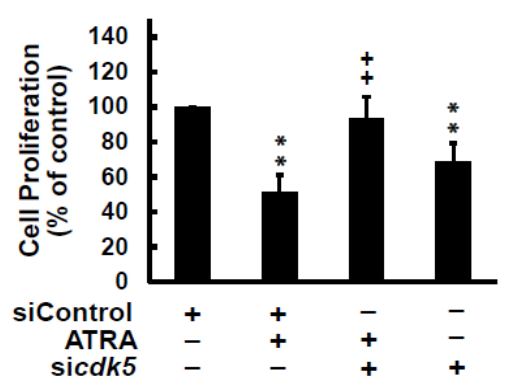

Fig. 5.Cdk5 is involved in ATRA-reduced proliferation of DU145 cells. A. After 24 h-pretreatment of serum deprivation, DU145 cells were treated as follows: control (DMSO, 0.1\%), ATRA (1 $\mu \mathrm{M})$, ATRA $(1 \mu \mathrm{M})+$ $\mathrm{RV}(1 \mu \mathrm{M})$, or RV $(1 \mu \mathrm{M})$ for $24 \mathrm{~h}$. B. DU145 cells were treated as follows: control (siControl, $5 \mathrm{pmol} / 10^{4}$ cells), ATRA $(1 \mu \mathrm{M})+$ siControl, ATRA $(1 \mu \mathrm{M})+$ sicdk5 (5 pmol/10 $10^{4}$ cells), or sicdk5 (5 pmol/104 cells). DU145 cell proliferation was measured by MTT assay as described in "Materials and Methods". The value of the control group is $100 \%$. The data are represented as the means \pm S.E. of the mean; **, $p<0.01$ versus control group;,$++ p<0.01$ versus ATRA group or ATRA + siControl group.
A

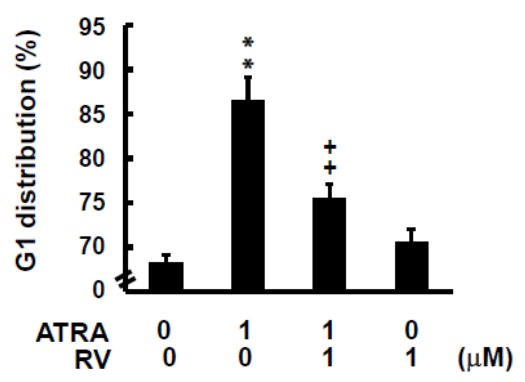

B

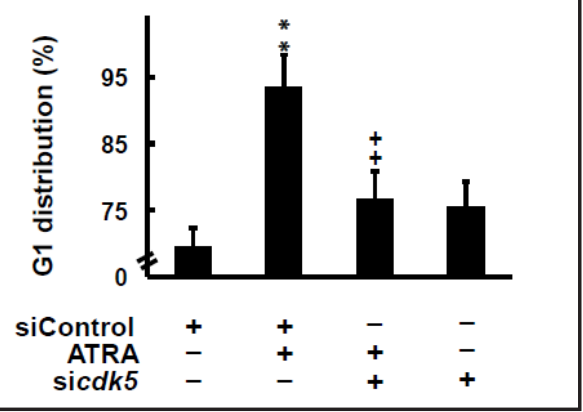

Fig. 6. Cdk5 is involved in ATRA-induced G1 phase accumulation of DU145 cells. After 24 h-pretreatment of serum deprivation, DU145 cells were treated as follows: control (DMSO, 0.1\%), ATRA (1 $\mu \mathrm{M})$, ATRA $(1 \mu \mathrm{M})$, ATRA $(1 \mu \mathrm{M})+\mathrm{RV}(1 \mu \mathrm{M})$, or RV (1 $\mu \mathrm{M})$ for $24 \mathrm{~h}$. B. DU145 cells were treated as follows: control (siControl, $5 \mathrm{pmol} / 10^{4}$ cells), ATRA $(1 \mu \mathrm{M})+$ siControl, ATRA $(1 \mu \mathrm{M})+\operatorname{sicdk5}\left(5 \mathrm{pmol} / 10^{4}\right.$ cells $)$, or sicdk5 ( $5 \mathrm{pmol} / 10^{4}$ cells). Cells were stained by propidium iodide for $30 \mathrm{~min}$ and followed by flow cytometry analysis as described in "Materials and Methods" ( $n=6)$. G1 phase accumulation of the cells is shown in the graph. The data are represented as the means \pm S.E. of the mean; ${ }^{* *}, p<0.01$ versus control group;,$++ p<0.01$ versus ATRA group or ATRA + siControl group.

5A). Furthermore, siRNA was used to knock down Cdk5 protein as described in Fig. 3B. Treatment of ATRA and siControl effectively decreased the proliferation of DU145 cells, whereas co-treatment of sicdk5 significantly reversed ATRA-induced effects (Fig. 5B). Interestingly, both treatments of RV or sicdk5 decreased the proliferation of DU145 cells compared with the respective control groups, which suggests that the Cdk5 protein and its activity are important to the growth of DU145 cells.

ATRA-induced G1 phase accumulation of DU145 cells can be reversed by Cdk5 inhibition Our previous results demonstrate that G1 phase accumulation in the cell cycle is an indicator for Cdk5-induced cell differentiation [34]. Here, the involvement of Cdk5 in the ATRA-induced changes was monitored by G1 phase accumulation. By using flow cytometry, the effects of treatments (as described in Fig. 5) on G1 accumulation of DU145 cells were quantified (Fig. 
Fig. 7. Scheme illustrating that ATRA might cause DU145 cell cycle arrest through Cdk5 activation and subsequent p27 expression.

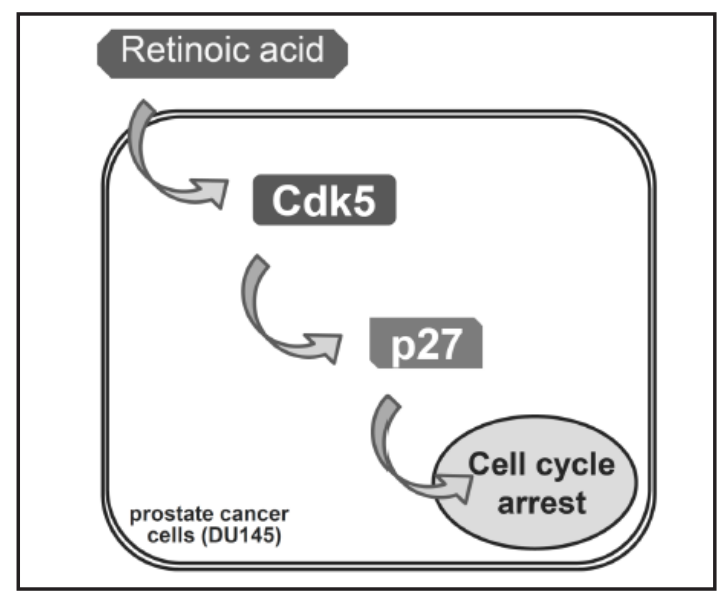

6). We found that the accumulation of DU145 cells in G1 phase was apparently increased by ATRA treatment in both Fig. 6A and 6B $(p<0.05)$. Co-treatment with RV or sicdk5 significantly reversed these effects ( $p<0.05$ compared with the ATRA group). In addition, treatment of RV alone or sicdk5 alone did not affect the G1 phase accumulation of DU145 cells compared with the respective control groups. Taken together, these results suggest that ATRA induces cell cycle arrest in G1 phase through Cdk5 activation.

\section{Discussion}

The clinical outcome and results are sometimes negative for castration-resistant prostate cancer patients [35]. Therefore, finding novel molecular therapeutic targets is important, as it will allow new strategies for treating castration-resistant prostate cancer (CRPC). Huss et al. reported that both in vitro and in vivo ATRA can slow prostate tumor cell proliferation, induce apoptosis, and block the emergence of the neuroendocrine phenotype [2]. Furthermore, their data suggest the differential regulation of p21 and p27 as a molecular mechanism whereby ATRA intervention therapy can inhibit the natural history of spontaneous prostate cancer [2]. Although the application of ATRA in prostate cancer is still controversial, it is worth investigating the molecular mechanism of ATRA, particularly from the perspective of a future combination therapy with other effective agents. Here, we used DU145 cells as a cell model of CRPC to investigate how ATRA and Cdk5 work together to halt the growth of cancer cells.

As our results showed, we found that $1 \mu \mathrm{M}$ ATRA treatment effectively inhibited cell proliferation of DU145 cells, while $0.1 \mu \mathrm{M}$ ATRA insignificantly increased it. This might be expected because a low concentration of ATRA can act as a vitamin for cell proliferation. The phenotypic characteristics of ATRA-treated DU145 cells were evaluated by microscopic inspection of the overall morphology. The spindle-like morphology and loosened attachment of the cells induced by ATRA indicated that ATRA treatments tend to retard the growth of DU145 cells. Our previous report indicates that Cdk5 can promote growth arrest and differentiation of pheochromocytoma cells [34] and that Cdk5 protein expression can be induced in neuronal cells by ATRA treatment [36]. On the other hand, Kawauchi et al. indicate that p27, which is a common cell cycle blocker, participates in cortical neuronal migration as a downstream target of Cdk5 [27]. p27 has also been reported to be related to a druginduced G1/S arrest of prostate cancer cells [37]. Taking these clues together, the working hypothesis here explored is that Cdk5 might be involved in ATRA-induced growth inhibition of DU145 cells through p27 (Fig. 7).

At first, protein expression was monitored after ATRA treatments. Meeting our expectations, ATRA treatments induced the protein expression of both Cdk5 and p27. The next question was whether p27 is regulated by Cdk5 under ATRA stimulation. Cdk5 
inhibition (by inhibitor or siRNA) was performed to see if the ATRA-induced p27 expression was affected. Roscovitine (RV), a potent inhibitor of Cdk5 kinase [20, 22], was used in this study to identify whether Cdk5 activation is involved in ATRA-affected DU145 cells. Our unpublished data indicated that RV even at $10 \mu \mathrm{M}$ does not affect other Cdk members, such as Cdc2, in prostate cancer cell lines. Indeed, blockade of Cdk5 did prevent the actions of ATRA on both the expression and subcellular localization of p27. A previous report indicated that Cdk5 interacts with p27 in the nuclei of neurons and inhibits cell cycle progression [33]. Once the distribution of Cdk5 and p27 in the nucleus decreases, the cell cycle proceeds as well [33]. This observation supports our hypothesis that ATRA increases Cdk5 and p27 in the nuclei of DU145 cells, which then results in growth inhibition.

Because Cdk5 inhibition effectively reverted the ATRA-induced decrease in proliferation of DU145 cells, it is interesting to clarify whether the ATRA-induced cell number decrease is due to cell cycle arrest or cell death. Our data indicated that ATRA did not induce apparent cell death (by live cell number counting) or apoptosis (sub G1 appearance analyzed by flow cytometry) in DU145 cells (data not shown). Therefore, the change in cell cycle became our main focus. By using a similar strategy to inhibit Cdk5 with or without ATRA treatments, the cell cycle distribution was detected by flow cytometry and demonstrates that ATRA could trigger G1 phase arrest of DU145 cells and Cdk5 inhibition could reverse it. These results are compatible with a study in neuronal cells showing that the nuclear localization of Cdk5 and p27 is responsible for the cell cycle arrest and differentiation [33]. On the other hand, Ananthanarayanan et al. collected a cohort of 202 recurrent cases (rise in prostatespecific antigen) and 202 matched controls without recurrence that were then studied by automated digital microscopy analysis of tissue microarrays [38]. Their result shows a strong correlation between increasing risk of recurrence of prostate cancer and low protein levels of p27 subcellular localization in both nucleus and cytoplasm, which suggests that a decrease in the nuclear distribution of p27 correlates with poor outcome of prostate cancer [38]. Based on these observations, ATRA might reduce the growth of recurrent prostate cancer cells through triggering of Cdk5 and subsequent p27 expression.

Our results are the first demonstration that ATRA might stimulate both Cdk5 activity and p27 expression, ultimately inhibiting the growth of prostate cancer cells (Fig. 7). We hope this finding might contribute to the future treatment of prostate cancer, especially in patients' nutritional control.

\section{Disclosure Statement}

The authors declare no conflict of interests.

\section{Acknowledgement}

This work was supported in part by Taiwan National Science Council (NSC96-2628-B005-013-MY3 and NSC97-2320-B-005-002-MY3), the Taiwan Ministry of Education under the Aiming for the Top University plan, and Chang Bing Show Chwan Memorial Hospital (CBSH 9905001), Taiwan.

\section{Reference}

1 Huynh CK, Brodie AM, Njar VC: Inhibitory effects of retinoic acid metabolism blocking agents (rambas) on the growth of human prostate cancer cells and lncap prostate tumour xenografts in scid mice. Br J Cancer 2006;94:513-523. 
2 Huss WJ, Lai L, Barrios RJ, Hirschi KK, Greenberg NM: Retinoic acid slows progression and promotes apoptosis of spontaneous prostate cancer. Prostate 2004;61:142-152.

- 3 Ades L, Guerci A, Raffoux E, Sanz M, Chevallier P, Lapusan S, Recher C, Thomas X, Rayon C, Castaigne S, Tournilhac O, de Botton S, Ifrah N, Cahn JY, Solary E, Gardin C, Fegeux N, Bordessoule D, Ferrant A, MeyerMonard S, Vey N, Dombret H, Degos L, Chevret S, Fenaux P: Very long-term outcome of acute promyelocytic leukemia after treatment with all-trans retinoic acid and chemotherapy: The european apl group experience. Blood 2010;115:1690-1696.

-4 Futami H, Sakai R: All-trans retinoic acid downregulates alk in neuroblastoma cell lines and induces apoptosis in neuroblastoma cell lines with activated alk. Cancer Lett 2010;297:220-225.

5 Kuo HS, Hsu FN, Chiang MC, You SC, Chen MC, Lo MJ, Lin H: The role of cdk5 in retinoic acid-induced apoptosis of cervical cancer cell line. Chin J Physiol 2009;52:23-30.

-6 Hong WK, Lippman SM, Itri LM, Karp DD, Lee JS, Byers RM, Schantz SP, Kramer AM, Lotan R, Peters LJ, et al.: Prevention of second primary tumors with isotretinoin in squamous-cell carcinoma of the head and neck. N Engl J Med 1990;323:795-801.

7 Anderson IC, Sugarbaker DJ, Ganju RK, Tsarwhas DG, Richards WG, Sunday M, Kobzik L, Shipp MA: Stromelysin-3 is overexpressed by stromal elements in primary non-small cell lung cancers and regulated by retinoic acid in pulmonary fibroblasts. Cancer Res 1995;55:4120-4126.

8 Jimenez-Lara AM, Aranda A, Gronemeyer H: Retinoic acid protects human breast cancer cells against etoposide-induced apoptosis by nf-kappab-dependent but ciap2-independent mechanisms. Mol Cancer 2010;9:15.

-9 Zou C, Ramakumar S, Qian L, Zang R, Wang J, Grossman HB, Lotan R, Liebert M: Effect of retinoic acid and interferon alpha-2a on transitional cell carcinoma of bladder. J Urol 2005;173:247-251.

10 Aebi S, Kroning R, Cenni B, Sharma A, Fink D, Los G, Weisman R, Howell SB, Christen RD: All-trans retinoic acid enhances cisplatin-induced apoptosis in human ovarian adenocarcinoma and in squamous head and neck cancer cells. Clin Cancer Res 1997;3:2033-2038.

11 Lotan R, Dawson MI, Zou CC, Jong L, Lotan D, Zou CP: Enhanced efficacy of combinations of retinoic acidand retinoid $x$ receptor-selective retinoids and alpha-interferon in inhibition of cervical carcinoma cell proliferation. Cancer Res 1995;55:232-236.

12 Soignet S, Fleischauer A, Polyak T, Heller G, Warrell RP Jr: All-trans retinoic acid significantly increases 5-year survival in patients with acute promyelocytic leukemia: Long-term follow-up of the new york study. Cancer Chemother Pharmacol 1997;40 Suppl:S25-29.

13 Hsu FN, Chen MC, Chiang MC, Lin E, Lee YT, Huang PH, Lee GS, Lin H: Regulation of androgen receptor and prostate cancer growth by cyclin-dependent kinase 5. J Biol Chem 2011;286:33141-33149.

14 Hsu FN, Yang MS, Lin E, Tseng CF, Lin H: The significance of her2 on androgen receptor protein stability in the transition of androgen requirement in prostate cancer cells. Am J Physiol Endocrinol Metab 2011;300:E902-908.

15 Tsai LH, Delalle I, Caviness VS, Jr., Chae T, Harlow E: P35 is a neural-specific regulatory subunit of cyclindependent kinase 5. Nature 1994;371:419-423.

16 Alvarez A, Munoz JP, Maccioni RB: A cdk5-p35 stable complex is involved in the beta-amyloid-induced deregulation of cdk5 activity in hippocampal neurons. Exp Cell Res 2001;264:266-274.

17 Ubeda M, Kemp DM, Habener JF: Glucose-induced expression of the cyclin-dependent protein kinase 5 activator p35 involved in alzheimer's disease regulates insulin gene transcription in pancreatic beta-cells. Endocrinology 2004;145:3023-3031.

18 Musa FR, Takenaka I, Konishi R, Tokuda M: Effects of luteinizing hormone, follicle-stimulating hormone, and epidermal growth factor on expression and kinase activity of cyclin-dependent kinase 5 in leydig tm3 and sertoli tm4 cell lines. J Androl 2000;21:392-402.

19 Lin H: The versatile roles of cyclin-dependent kinase 5 in human diseases. Adapt Med 2009;1:22-25.

20 Lin H, Chen MC, Chiu CY, Song YM, Lin SY: Cdk5 regulates stat3 activation and cell proliferation in medullary thyroid carcinoma cells. J Biol Chem 2007;282:2776-2784.

21 Chen MC, Huang CY, Hsu SL, Lin E, Ku CT, Lin H, Chen CM: Retinoic acid induces apoptosis of prostate cancer du145 cells through cdk5 overactivation. Evid Based Complement Alternat Med 2012;2012:580736. 
22 Lin H, Juang JL, Wang PS: Involvement of cdk5/p25 in digoxin-triggered prostate cancer cell apoptosis. J Biol Chem 2004;279:29302-29307.

23 Hsu FN, Chen MC, Lin KC, Peng YT, Li PC, Lin E, Chiang MC, Hsieh JT, Lin H: Cyclin-dependent kinase 5 modulates stat 3 and androgen receptor activation through phosphorylation of $\operatorname{ser}(7)(2)(7)$ on stat 3 in prostate cancer cells. Am J Physiol Endocrinol Metab 2013;305:E975-986.

24 Brown AM, Riddoch FC, Robson A, Redfern CP, Cheek TR: Mechanistic and functional changes in ca2+ entry after retinoic acid-induced differentiation of neuroblastoma cells. Biochem J 2005;388:941-948.

25 Chen F, Wang Q Wang X, Studzinski GP: Up-regulation of egr1 by 1,25-dihydroxyvitamin d3 contributes to increased expression of p35 activator of cyclin-dependent kinase 5 and consequent onset of the terminal phase of hl60 cell differentiation. Cancer Res 2004;64:5425-5433.

26 Hsu SL, Hsu JW, Liu MC, Chen LY, Chang CD: Retinoic acid-mediated g1 arrest is associated with induction of p27(kip1) and inhibition of cyclin-dependent kinase 3 in human lung squamous carcinoma ch27 cells. Exp Cell Res 2000;258:322-331.

27 Kawauchi T, Chihama K, Nabeshima Y, Hoshino M: Cdk5 phosphorylates and stabilizes p27kip1 contributing to actin organization and cortical neuronal migration. Nat Cell Biol 2006;8:17-26.

28 Wang HY, Lin WY, Chen MC, Lin T, Chao CH, Hsu FN, Lin E, Huang CY, Luo TY, Lin H: Inhibitory effects of rhenium-188-labeled herceptin on prostate cancer cell growth: A possible radioimmunotherapy to prostate carcinoma. Int J Radiat Biol 2013;89:346-355.

29 Huang PH, Huang CY, Chen MC, Lee YT, Yue CH, Wang HY, Lin H: Emodin and aloe-emodin suppress breast cancer cell proliferation through er alpha inhibition. Evid Based Complement Alternat Med 2013;2013:376123.

-30 Lin H, Lin TY, Juang JL: Abl deregulates cdk5 kinase activity and subcellular localization in drosophila neurodegeneration. Cell Death Differ 2007;14:607-615.

-31 Lin H, Chen MC, Ku CT: Cyclin-dependent kinase 5 regulates steroidogenic acute regulatory protein and androgen production in mouse leydig cells. Endocrinology 2009;150:396-403.

32 Lin H, Wang PS: Inhibitory effects of digoxin on testosterone production in rat leydig cells. Adapt Med 2012;4:165-173.

33 Zhang J, Li H, Herrup K: Cdk5 nuclear localization is p27-dependent in nerve cells: Implications for cell cycle suppression and caspase-3 activation. J Biol Chem 2010;285:14052-14061.

-34 Chen MC, Lin H, Hsu FN, Huang PH, Lee GS, Wang PS: Involvement of camp in nerve growth factor-triggered p35/cdk5 activation and differentiation in pc12 cells. Am J Physiol Cell Physiol 2010;299:C516-527.

-35 Foley R, Marignol L, Keane JP, Lynch TH, Hollywood D: Androgen hypersensitivity in prostate cancer: Molecular perspectives on androgen deprivation therapy strategies. Prostate 2011;71:550-557.

-36 Lee JH, Kim KT: Induction of cyclin-dependent kinase 5 and its activator p35 through the extracellularsignal-regulated kinase and protein kinase a pathways during retinoic-acid mediated neuronal differentiation in human neuroblastoma sk-n-be(2)c cells. J Neurochem 2004;91:634-647.

37 Wang CD, Huang JG, Gao X, Li Y, Zhou SY, Yan X, Zou A, Chang JL, Wang YS, Yang GX, He GY: Fangchinoline induced g1/s arrest by modulating expression of p27, pcna, and cyclin d in human prostate carcinoma cancer pc3 cells and tumor xenograft. Biosci Biotechnol Biochem 2010;74:488-493.

38 Ananthanarayanan V, Deaton RJ, Amatya A, Macias V, Luther E, Kajdacsy-Balla A, Gann PH: Subcellular localization of p27 and prostate cancer recurrence: Automated digital microscopy analysis of tissue microarrays. Hum Pathol 2011;42:873-881. 